EXTENDED REPORT

\title{
Oncostatin $M$ in combination with tumour necrosis factor $\alpha$ induces a chondrocyte membrane associated aggrecanase that is distinct from ADAMTS aggrecanase- 1 or -2
}

\author{
W Hui, H E Barksby, D A Young, T E Cawston, N McKie, A D Rowan
}

Ann Rheum Dis 2005;64:1624-1632. doi: 10.1136/ard.2004.028191

See end of article for authors' affiliations

Correspondence to: Dr A D Rowan,

Musculoskeletal Research Group, Medical School, University of Newcastle upon Tyne, Newcastle NE2 4HH, UK; A.D.Rowan@ ncl.ac.uk

Accepted 6 April 2005 Published Online First 5 May 2005

\begin{abstract}
Objective: To determine whether oncostatin M (OSM) + tumour necrosis factor $\alpha$ (TNF $\alpha$ ) induces aggrecanase activity in chondrocyte membranes, to determine the effects of transforming growth factor $\beta 1$ (TGF $\beta 1$ ), interleukin 4 (IL4), and tissue inhibitor of metalloproteinases (TIMPs) on this activity, and to determine whether this activity is due to a known ADAMTS aggrecanase.

Methods: Aggrecanase activity and ability of agents to prevent membrane associated aggrecanase activity were assessed by Western blotting. Expression of known aggrecanases was measured by real time polymerase chain reaction in bovine nasal and human articular chondrocytes.

Results: Chondrocyte membrane associated aggrecanase activity and increased mRNA expression of ADAMTS-1, $-4,-5$, and -9 , but not ADAMTS- 4 or -15 , were enhanced after stimulation by OSM+TNF $\alpha$ in bovine chondrocytes. This activity was inhibited by TIMP-3. In human chondrocytes, OSM+TNF $\alpha$ also enhanced ADAMTS- 1 and -4 expression, but not that of other ADAMTSs. TNF $\alpha$ alone induced ADAMTS-9 expression, whereas OSM addition caused suppression. Both TGF $\beta 1$ and IL4 blocked membrane associated aggrecanase activity and decreased OSM+TNF $\alpha$-induced expression of ADAMTS-9 in bovine and human chondrocytes. IL4 down regulated ADAMTS-4 mRNA, whereas TGF $\beta 1$ increased this expression in both bovine and human chondrocytes.

Conclusions: OSM+TNF $\alpha$ up regulates membrane associated aggrecanase activity and several ADAMTS aggrecanase mRNAs in chondrocytes. The chondroprotective effects of IL4 and TIMP-3 suggest that they may have therapeutic benefit for aggrecanolysis, whereas the differential inhibitory effects of TGF $\beta 1$ may limit its therapeutic potential. Induced membrane associated aggrecanase activity is distinct from known soluble ADAMTS aggrecanases and merits further investigation.
\end{abstract}

artilage degradation leading to a loss of joint function in the arthritides involves proteolytic cleavage of both aggrecan and collagen. Loss of aggrecan from the cartilage extracellular matrix is an early and sustained feature of joint degeneration as is seen in both osteoarthritis (OA) and rheumatoid arthritis (RA). Matrix metalloproteinases (MMPs) cleave the aggrecan core protein at the Asn341-Phe342 bond, ${ }^{1}$ but the proteolytic fragments generated are retained within the tissue, suggesting that MMPs may not be responsible for pathological aggrecan degradation. ${ }^{2}$ Proteolysis at the Glu373-Ala374 bond within the interglobular domain of aggrecan is mediated by proteinases called aggrecanases, ${ }^{1}$ which release the glycosaminoglycanrich C-terminus of aggrecan that is important for the mechanical properties of cartilage. Aggrecanases are metalloproteinases that belong to a subfamily of the A Disintegrin and Metalloproteinase (ADAM) proteinases that contain thrombospondin motifs, the ADAMTSs. Although aggrecanase- 1 and -2 (ADAMTS-4 and -5) were first reported and implicated in cartilage degradation, ${ }^{3} 4$ ADAMTS- $1,-4,-5,-8$, -9 , and -15 are now referred to as aggrecanases. ${ }^{3-8}$ Aggrecan fragments generated by aggrecanase activity have been identified in cartilage explant cultures in vitro, as well as in human synovial fluid and cartilage tissues. ${ }^{2} 910$

Data implicating ADAMTS-4 and -5 in aggrecanolysis are, however, conflicting and contradictory. Some studies on aggrecanase expression have found raised mRNA levels, whereas others have failed to see regulation even after cytokine stimulation. ${ }^{11-15}$ It has been suggested that both these aggrecanases are important in $\mathrm{OA}$, based on in vitro observations with a hydroxamate compound that inhibits both MMPs and aggrecanases, ${ }^{16}$ while mRNA profiling data for OA have suggested that ADAMTS-5 and not ADAMTS- 4 is the pathophysiologically relevant aggrecanase, ${ }^{13}$ and decreased levels of ADAMTS-1, -5 , and -9 have also been reported. ${ }^{17}$ ADAMTS-4 mRNA is up regulated by cytokines such as interleukin 1 (IL) 1 and tumour necrosis factor $(\mathrm{TNF} \alpha)$, while ADAMTS- 1 is down regulated by ILl. ${ }^{18}{ }^{19}$ ADAMTS-5 mRNA has been shown to be expressed in synovium, although it is not regulated by either ILl or retinoic acid. ${ }^{12}$ ADAMTS- 1 and -8 are anti-angiogenic, ${ }^{20}$ suggesting that they are likely to have anabolic effects on cartilage. ADAMTS-9 is expressed in embryonic and adult tissues, and to date no physiological roles have been ascribed to ADAMTS-9 or $-15 .^{72}$

$\mathrm{TNF} \alpha$ is an important mediator in RA pathogenesis, and anti-TNF $\alpha$ treatment reduces inflammation, joint destruction, and serum MMP levels. ${ }^{22}$ This proinflammatory cytokine stimulates cartilage aggrecan and collagen release and

Abbreviations: ADAMTS, A Disintegrin And Metalloproteinase ThromboSpondin motif; GAPDH, glyceraldehyde-3-phosphate dehydrogenase; IL, interleukin; MMPs, matrix metalloproteinases; OA, osteoarthritis; OSM, oncostatin M; PBS, phosphate buffered saline; PCR, polymerase chain reaction; PMSF, phenylmethylsulphonyl fluoride; RA, rheumatoid arthritis; TFG $\beta$, transforming growth factor $\beta$; TIMPs, tissue inhibitors of metalloproteinases; TNF $\alpha$, tumour necrosis factor $\alpha$ 
inhibits their synthesis by chondrocytes. ${ }^{23} 24$ Furthermore, synovial fluid $\mathrm{TNF} \alpha$ levels correlate with cartilage degradation. $^{25}$ Oncostatin $M$ (OSM) is known to induce joint inflammation and cartilage damage, ${ }^{26-28}$ and has been localised to macrophages in rheumatoid synovium. ${ }^{28}$ Moreover, raised levels of OSM are detected in RA synovial fluids, ${ }^{28}$ and these levels correlate with joint inflammation and the markers of aggrecan degradation in RA. ${ }^{25}$ Blockade of OSM ameliorates joint inflammation and cartilage damage in collagen induced arthritis. ${ }^{30}$ Furthermore, OSM is an important co-factor in both ILl and TNF $\alpha$ mediated cartilage and bone damage and inflammation in arthritis. ${ }^{26} 27$

IL4 and transforming growth factor $\beta 1(\mathrm{TGF} \beta 1)$ are both major chondroprotective factors which can protect cartilage from degradation. ${ }^{30-34}$ IL4 suppresses synovial ILl levels and prevents the activation of pro-MMPs. ${ }^{30}$ TGF $\beta$ is an important anabolic regulator of cartilage ${ }^{34}$; it stimulates the synthesis of matrix components, and blocks cytokine induced degradation by down regulating MMPs and up regulating tissue inhibitors of metalloproteinases (TIMPs). ${ }^{33-35}$ Recently, TGF $\beta$ has been found to stimulate ADAMTS- 4 expression and aggrecanolysis in cartilage. ${ }^{15}$

TIMPs are important metalloproteinase regulators in extracellular matrix biology, and four have been identified in human synovium and cartilage that are regulated by growth factors and cytokines. ${ }^{35}$ TIMP-3 potently inhibits ADAMTS -4 and $-5,{ }^{36}{ }^{37}$ and blocks aggrecanolysis from bovine and porcine cartilages. ${ }^{38}$ Conversely, the other TIMPs which efficiently inhibit many MMPs, are poor inhibitors of ADAMTS-4 and $-5^{36} 37$ and fail to prevent aggrecanolysis, although all TIMPs block cartilage collagenolysis. ${ }^{39}$

We have shown that OSM in combination with ILl or $\mathrm{TNF} \alpha$ induces synergistic cartilage proteoglycan degradation in vitro and in vivo, ${ }^{26-29}{ }^{40}$ and that ILl+OSM up regulates a chondrocyte membrane associated aggrecanase activity. ${ }^{41}$ In this study we investigated whether this membrane associated aggrecanase activity can be induced by OSM+TNF $\alpha$, if TGF $\beta$, IL4 or TIMPs can modulate this activity, and whether this activity can be attributed to one of the known ADAMTS aggrecanases.

\section{MATERIALS AND METHODS}

Chemicals were obtained from the following suppliers: human recombinant TNF $\alpha$, IL4, and TGF $\beta 1$ were purchased from R\&D Systems (Abingdon, UK). OSM was a gift from Professor JK Heath (Birmingham, UK). The polyclonal antibody R663 was raised in a rabbit against the keyhole limpet haemocyanin conjugated peptide Ala-Arg-Gly-SerVal-Ile-Cys-Gly-COOH, corresponding to the amino terminus generated by cleavage of aggrecan at the Glu373-Ala374 peptide bond, and was generously supplied by Dr DJ Buttle (University of Sheffield, UK). ${ }^{42}$ Recombinant human TIMP-1 and TIMP-3, and native human TIMP-2 were produced inhouse. ${ }^{43-45}$ Primers and probes for human glyceraldehyde-3phosphate dehydrogenase (GAPDH) and bovine ribosomal 18S were purchased from Applied Biosystems (Warrington, UK), and all other oligonucleotides were obtained from Sigma (Poole, UK). Chondroitinase ABC (catalogue No 320301) and keratanase (catalogue No 320321) were purchased from ICN Biomedicals Ltd (Thame, UK). All other chemical and biochemicals were commercially available analytical grade reagents obtained from Fisons (Loughborough, UK) or Sigma, or have been previously described. ${ }^{26-28}$

\section{Chondrocyte culture and membrane preparation}

Chondrocytes were isolated from bovine nasal septum cartilage samples and human knee joints, as previously described. ${ }^{26-28}$ Cells were incubated in fresh serum-free
Dulbecco's modified Eagle's medium containing $25 \mathrm{mM}$ HEPES (Gibco, Paisley, UK) supplemented with glutamine (2 $\mathrm{mmol} / \mathrm{l})$, streptomycin $(100 \mu \mathrm{g} / \mathrm{ml})$, penicillin $(100 \mathrm{U} / \mathrm{ml})$, amphotericin B $(2.5 \mu \mathrm{g} / \mathrm{ml})$, and $10 \%$ ( $\mathrm{vol} / \mathrm{vol})$ fetal calf serum in a humidified atmosphere of $95 \%$ air $/ 5 \% \mathrm{CO}_{2}$ at $37^{\circ} \mathrm{C}$. When cells reached $80-90 \%$ confluence, the medium was removed and replaced with serum-free medium overnight and then cultured in fresh medium containing test cytokines for the indicated time periods.

Chondrocyte membrane purification was adapted from that previously described. ${ }^{41}$ Briefly, media were removed and the stimulated bovine nasal chondrocyte monolayer was washed twice with ice cold phosphate buffered saline (PBS), harvested into PBS using a scraper, and the cell pellet resuspended in lysis buffer $(10 \mathrm{mM}$ Tris/HCl, $\mathrm{pH} 7.4$, containing $8.5 \%$ (wt/vol) sucrose, $1 \mathrm{mM} N$-ethylmaleimide, $1 \mathrm{mM}$ phenylmethylsulphonyl fluoride (PMSF), and $10 \mu \mathrm{g} /$ $\mathrm{ml}$ soybean trypsin inhibitor). Cells were lysed by sonication, and unlysed cells and cell nuclei were removed by centrifugation at $1700 \mathrm{~g}$ for 10 minutes at $4^{\circ} \mathrm{C}$. The supernatant was collected and then centrifuged at $33000 \mathrm{~g}$ for 1.5 hours at $4^{\circ} \mathrm{C}$ to pellet the membrane fraction, which was resuspended in $1 \mathrm{ml}$ of lysis buffer. After centrifugation at $150000 \mathrm{~g}$ for 1.5 hours at $4^{\circ} \mathrm{C}$ and layering of $0.5 \mathrm{ml}$ of the sample on top of $10 \mathrm{ml}$ of $17 \%(\mathrm{wt} / \mathrm{vol})$ sucrose, the resultant pellet was resuspended in $10 \mathrm{mM}$ Tris/ $\mathrm{HCl}, \mathrm{pH} \mathrm{7.4}$, assessed for 5'nucleotidase activity as an indicator of plasma membrane enrichment, ${ }^{46}$ and stored at $-20^{\circ} \mathrm{C}^{41}$ Protein concentration was determined by the BCA protein assay (Pierce, Rockford, Illinois, USA).

\section{Aggrecan preparation}

Aggrecan was prepared from bovine nasal septum cartilage using a modification of an established protocol. ${ }^{47}$ Briefly, cartilage was cut into $2 \mathrm{~mm}^{3}$ pieces and added to 10 volumes of extraction buffer (4 M guanidinium chloride, $50 \mathrm{mM}$ sodium acetate, $\mathrm{pH}$ 6.0, $2 \mathrm{mM}$ PMSF, $5 \mathrm{mM}$ benzamidine$\mathrm{HCl}, 10 \mathrm{mM}$ EDTA, $0.1 \mathrm{mM}$ 6-aminohexanoic acid) at $4^{\circ} \mathrm{C}$. The mixture was stirred for 48 hours at $4^{\circ} \mathrm{C}$, and aggrecan isolated by $1.45 \mathrm{~g} / \mathrm{ml}$ caesium density gradient centrifugation at $100000 \mathrm{~g}$ for 48 hours at $10^{\circ} \mathrm{C}$. Purified aggrecan was dialysed exhaustively into $10 \mathrm{mM}$ Tris/acetate, $\mathrm{pH}$ 7.4, before storage at $-20^{\circ} \mathrm{C}^{41}$ Aliquots of the aggrecan were treated with chondroitinase $\mathrm{ABC}$ lyase at $2.5 \mathrm{mU} / \mathrm{mg}$ of proteoglycan, and keratinase at $50 \mathrm{mU} / \mathrm{mg}$ of proteoglycan, in the presence of proteinase inhibitors for 5 hours at $37^{\circ} \mathrm{C}$ to remove chondroitin and keratan sulphate chains. This deglycosylated aggrecan was dialysed against $10 \mathrm{mM}$ Tris/ $\mathrm{HCl}, \mathrm{pH} 7.4$, and stored at $-20^{\circ} \mathrm{C}$, and used in all experiments as the aggrecanase substrate. ${ }^{41}$

\section{Chondrocyte membrane associated aggrecanase activity assay}

The membrane preparation ( $50 \mu \mathrm{g}$ of protein) was incubated in the presence of the bovine aggrecan substrate $(100 \mu \mathrm{g}$ protein) in Tris buffer ( $\mathrm{pH} 7.4$ ) containing $10 \mathrm{mM} \mathrm{CaCl}_{2}$ for 16 hours at $37^{\circ} \mathrm{C}^{41}$ Samples were then boiled for 5 minutes and subjected to electrophoresis on $10 \%$ sodium dodecyl sulphate/polyacrylamide gel electrophoresis gels and the separated proteins transferred to nitrocellulose. After blocking, the membrane was incubated overnight with anti(aggrecan neoepitope)antibody (R663) diluted 1:200 in Tris buffered saline containing $0.1 \%$ ( $\mathrm{vol} / \mathrm{vol})$ Tween 20 with $1 \%$ (wt/vol) milk powder. The blots were then incubated for 1 hour with anti-(rabbit IgG)-horseradish peroxidase conjugate diluted 1:1000. The cleaved aggrecan was visualised by enhanced chemiluminescence (Amersham Biosciences, Little Chalfont, UK). 


\begin{tabular}{|c|c|c|}
\hline Gene & Human & Bovine \\
\hline \multicolumn{3}{|l|}{ ADAMTS-1 } \\
\hline Forward & 5'-GGACAGGTGCAAGCTCATCTG-3' & 5'-TTCAACGCCATCCCTACTTTCTCG-3' \\
\hline Reverse & 5'-TCTACAACCTTGGGCTGCAAA-3' & 5'-CCCACTGCCCCCTGTCCCTCAAC-3' \\
\hline \multicolumn{3}{|l|}{ ADAMTS-4 } \\
\hline Forward & 5'-CAAGGTCCCATGTGCAACGT-3' & 5'-GCGCCCGCTTCATCACT-3' \\
\hline Reverse & $5^{\prime}$-CATCTGCCACCACCAGTGTCT-3' & 5'-GCAGCGGCCACCCATAC-3' \\
\hline \multicolumn{3}{|l|}{ ADAMTS-5 } \\
\hline Forward & 5'-TGTCCTGCCAGCGGATGT-3' & 5'-TGACGCGGCCATCCTGTTTACT-3' \\
\hline Reverse & 5'-ACGGAATACTGTACGGCCTACA-3' & 5'-GGAGGCCATCGTCTTCAATCACC-3' \\
\hline \multicolumn{3}{|c|}{ 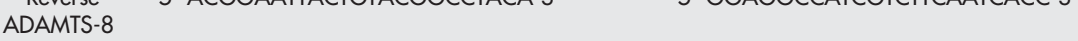 } \\
\hline Forward & $5^{\prime}$-CCGCCACCCAGAGCACTA-3' & 5'-AGATCTTGGGGCTGGGCTCC-3' \\
\hline Reverse & 5'-TCGATCACGGAGCAGCTTTT-3' & 5'-GGCTGGCATTCCTCGTGTGG-3' \\
\hline \multirow{2}{*}{\multicolumn{3}{|c|}{ 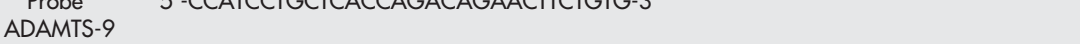 }} \\
\hline & & \\
\hline Forward & 5'-GATACCTTAGGCCTGGCTGAACTG-3' & 5'-CTGGGTTACCGCACATTAGACAT-3' \\
\hline Reverse & 5'-GCGATCGTAAAAGCTGTAATCC-3' & 5'-TAGCGCCAGCCACCAGTATTA-3' \\
\hline \multicolumn{3}{|l|}{ ADAMTS-15 } \\
\hline Forward & 5'-ATGTGCTGGCACCCAAGGT-3' & 5'-GACACGGCCATCCTCTTCACTCG-3' \\
\hline Reverse & 5'-CAGCCAGCCTTGATGCACTT-3' & 5'-AGCAGCTCCTCTTGGGGTCACAC-3 \\
\hline Probe & 5'-CCTGACTCCACCTCCGTCTGTGTCCA-3' & \\
\hline
\end{tabular}

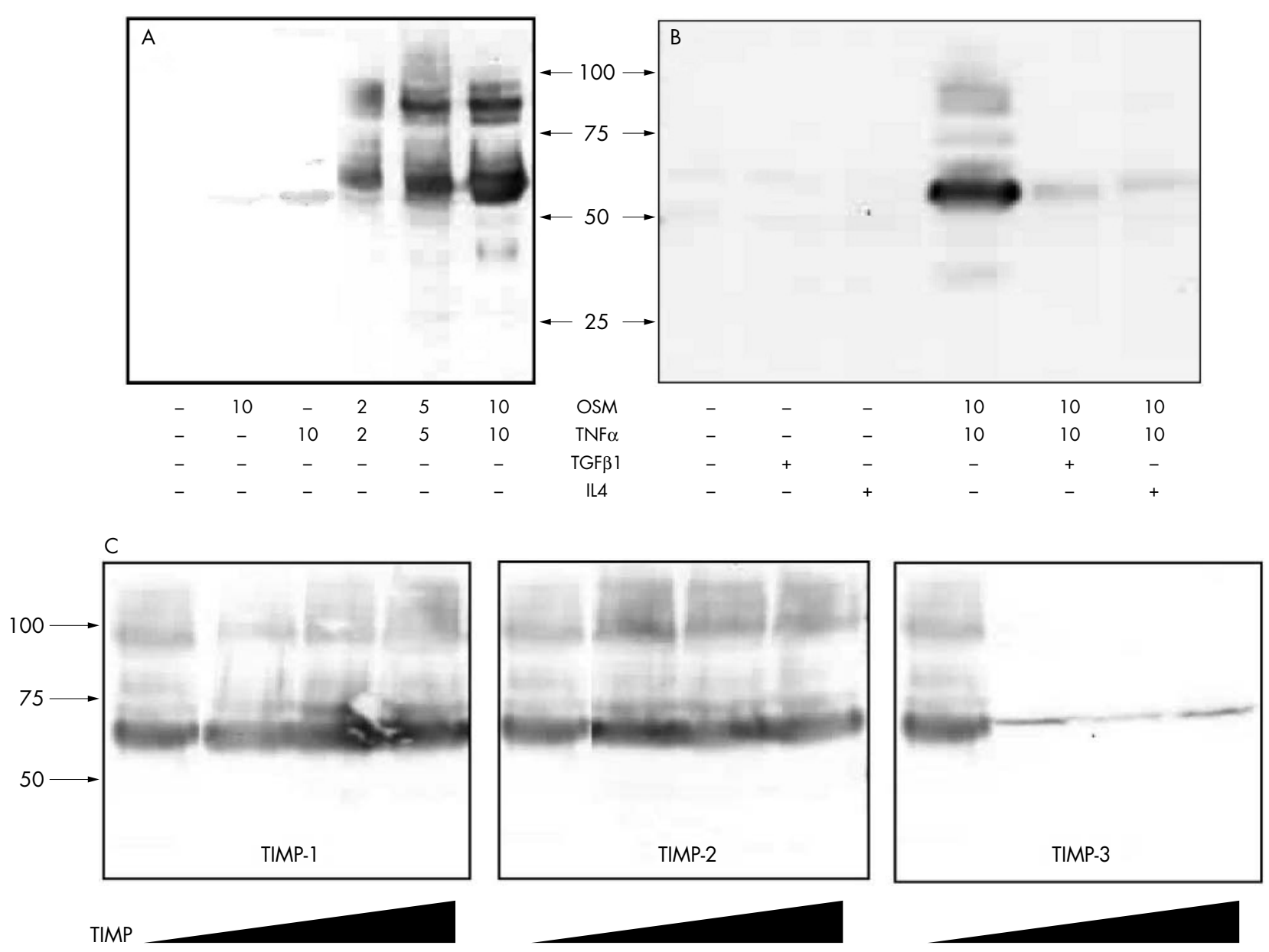

Figure 1 Effect of cytokines and TIMPs on chondrocyte membrane associated aggrecanase activity. Bovine nasal chondrocytes were cultured until 80$90 \%$ confluence, serum starved overnight, and then stimulated with various cytokines individually or in combination for 24 hours. Harvested cells were lysed and the plasma membrane fraction enriched by density centrifugation. Membranes (50-100 $\mu \mathrm{g}$ ) were incubated with deglycosylated aggrecan $(100 \mu \mathrm{g})$ at $37^{\circ} \mathrm{C}$ for 16 hours. Aggrecanase activity was examined by Western blot using an antibody (R663) that recognises the neoepitope generated after cleavage of aggrecan at the Glu373-Ala374 bond. (A) Effect of cytokine dose on the membrane activity; (B) effect of TGF 31 (15 ng/ $\mathrm{ml})$ or IL4 $(25 \mathrm{ng} / \mathrm{ml})$ inclusion in the 24 hour chondrocyte stimulation; (C) the effect of TIMP-1, -2, and $-3(0.1,0.5$, or $1.5 \mu \mathrm{g})$, added for 30 minutes at room temperature before the addition of substrate. The data shown are representative of three separate chondrocyte preparations. 
Bovine
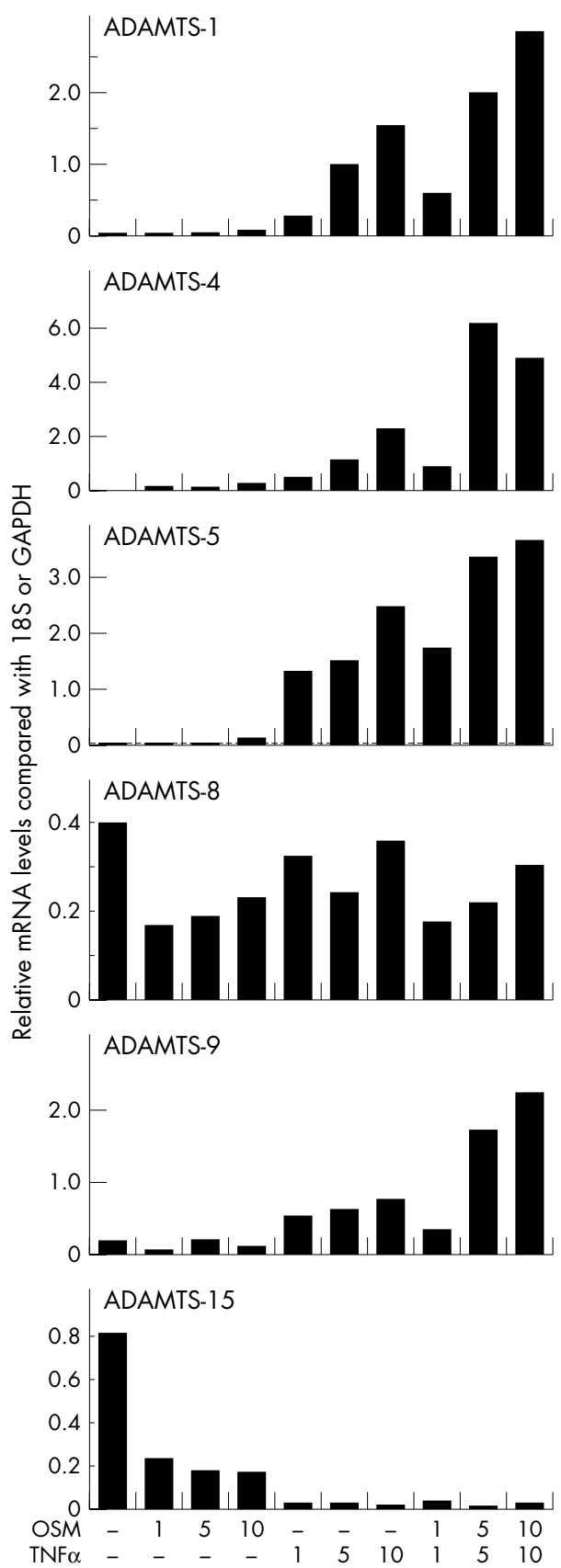

Human
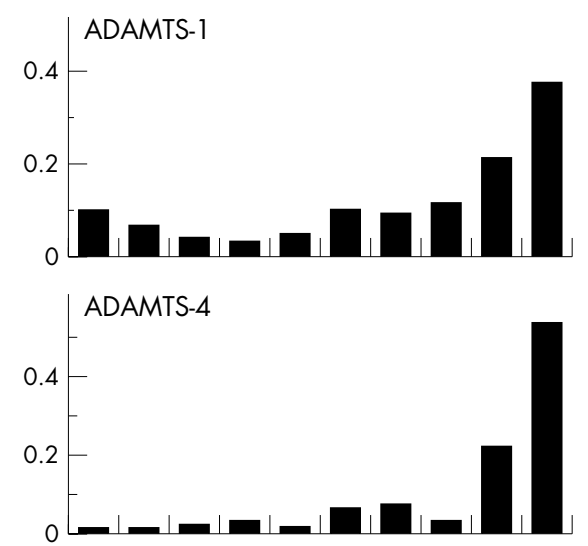

ADAMTS-5

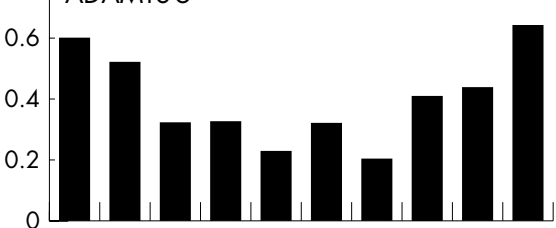

Figure 2 Effects of OSM and TNF $\alpha$ on the expression of ADAMTS aggrecanases in chondrocytes. Bovine nasal or human articular chondrocytes were cultured until $80-90 \%$ confluence and then serum starved overnight. Cells were stimulated with OSM. TNF $\alpha$ alone or in combination for 24 hours. Total RNA was isolated, reverse transcribed, and the resulting CDNA used in a separate real time PCR with specific primers for ADAMTS-1, $-4,-5,-8,-9$, or -15. No signal was detected for ADAMTS-8 in human chondrocytes with any treatment. Results were normalised to either 18S (for bovine) or GAPDH (for human) and are presented graphically as relative mRNA levels. ${ }^{48}$ The data shown are representative of two separate chondrocyte preparations.

Real time polymerase chain reaction (PCR)

Total cellular RNA was isolated and purified using the RNeasy kit (Qiagen, Crawley, UK). RNA ( $1 \mu \mathrm{g}$ ) was reverse transcribed in a $20 \mu \mathrm{l}$ reaction using random hexamers and Superscript II reverse transcriptase (Invitrogen, Paisley, UK), according to the manufacturer's instructions. ${ }^{48}$ Oligonucleotide primers were designed using Primer Express 1.0 software (Applied Biosystems). To prevent amplification of any contaminating genomic DNA, the primers were located within different exons close to, or spanning, the intron/exon boundary. Table 1 outlines the primer sequences.

Relative measurement of human gene expression was performed using a Lightcycler (Roche Diagnostics Ltd, Lewes, UK) or an ABI 7900HT. PCRs were performed in triplicate in $5 \mathrm{mM} \mathrm{MgCl}, 2 \mu \mathrm{l}$ of Hotstart SYBR Green Master Mix (Roche), $0.5-1.0 \mu \mathrm{mol} / \mathrm{l}$ of each primer in a $20 \mu \mathrm{l}$ reaction. Thermocycler conditions comprised an initial activation step at $95^{\circ} \mathrm{C}$ for 10 minutes. This was followed by a three step 
Bovine
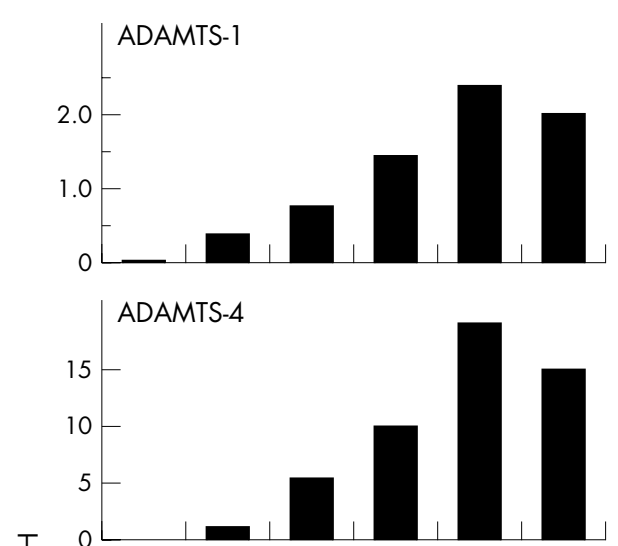

I
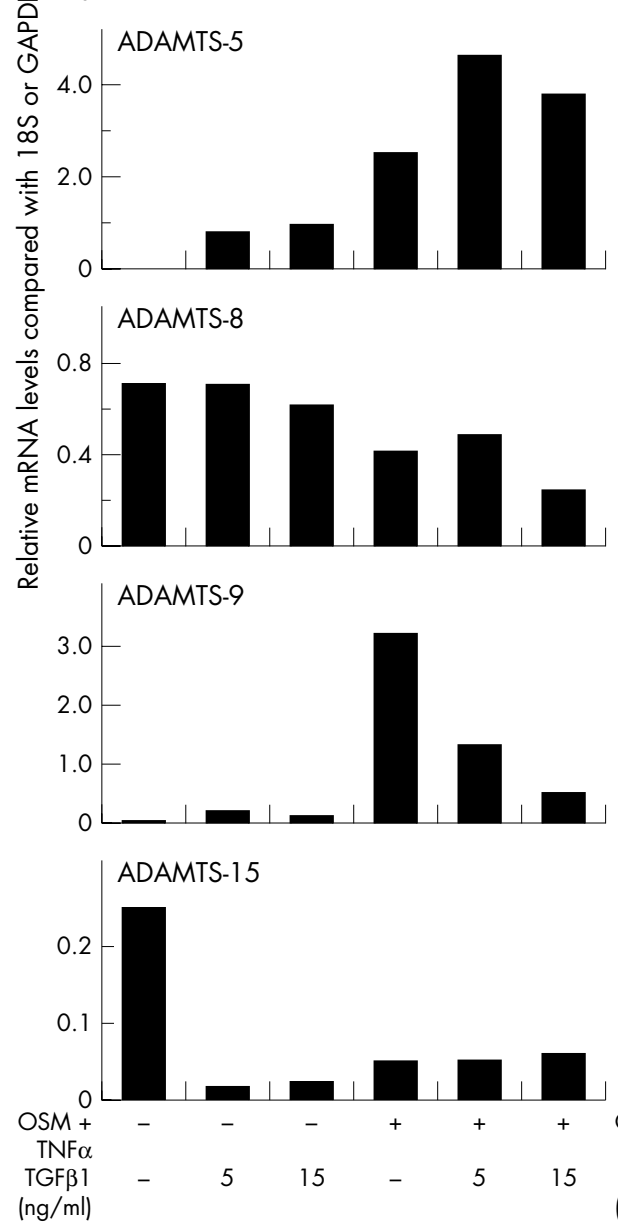

Human

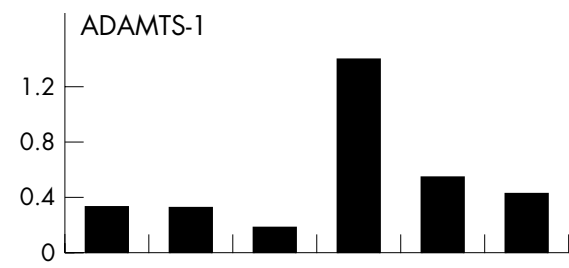

ADAMTS-4

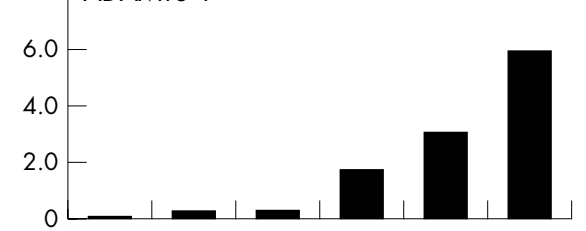

ADAMTS-5
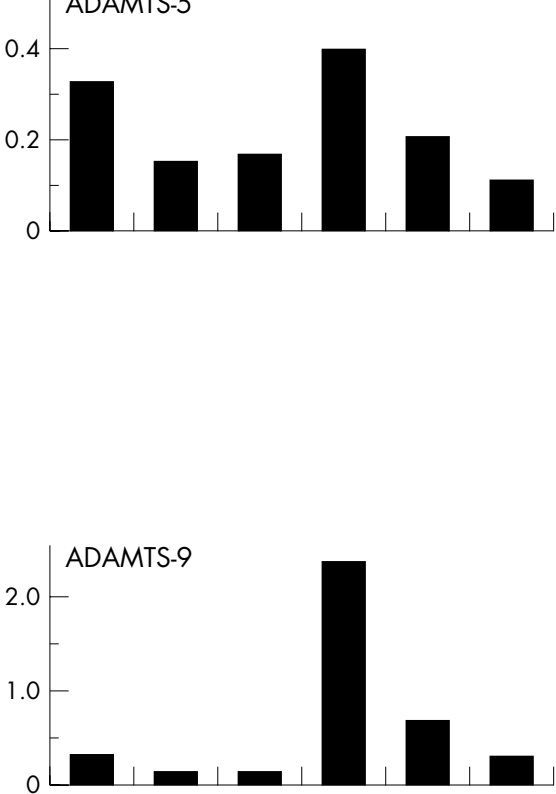

ADAMTS-15

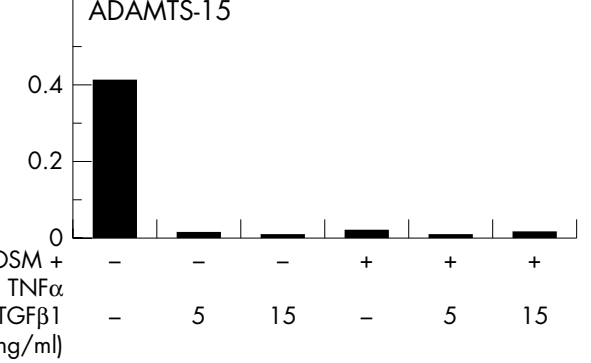

Figure 3 Effects of TGF $\beta 1$ on OSM+TNF $\alpha$-induced ADAMTS aggrecanases. Bovine nasal or human articular chondrocytes were stimulated with OSM+TNF $\alpha$ (both at $10 \mathrm{ng} / \mathrm{ml}$ ) \pm TGF $\beta 1$ for 24 hours. Real time PCR was performed on isolated RNA, and the normalised results presented graphically as described in fig 2. No signal was detected for ADAMTS-8 in human chondrocytes with any treatment. The data shown are representative of two separate chondrocyte preparations.

programme consisting of $95^{\circ} \mathrm{C}$ for 20 seconds, $60^{\circ} \mathrm{C}$ for 5 seconds, and $72^{\circ} \mathrm{C}$ for 10 seconds for 45 cycles. A one step melt curve analysis was also performed at the end of each run to ensure the crossover values obtained were due to the amplification of a single specific product. ${ }^{48}$ For TaqMan reactions, VIC or FAM labelled probes were used with an initial step of $50^{\circ} \mathrm{C}$ for 2 minutes, then $95^{\circ} \mathrm{C}$ for 10 minutes, followed by a two step programme of $95^{\circ} \mathrm{C}$ for 15 seconds and $60^{\circ} \mathrm{C}$ for 1 minute for 45 cycles, according to the manufacturer's instructions. Bovine genes were assessed using SYBR
Green (Cambrex, Wokingham, UK), essentially as above after optimisation.

\section{RESULTS}

OSM in combination with TNF $\alpha$ induces a chondrocyte membrane associated aggrecanase activity that is inhibited by TIMP-3

Stimulation of bovine nasal chondrocytes with OSM or TNF $\alpha$ alone induced very low levels of the membrane associated aggrecanase at 24 hours, although for TNF $\alpha$ this 
level of activity increased at 48 hours (not shown). When OSM was combined with TNF $\alpha$, a marked dose dependent increase in membrane associated aggrecanase activity was found (fig 1A). The pattern of aggrecan fragments generated containing the aggrecanase neoepitope was very similar to that previously reported for ILI+OSM. ${ }^{41}$ Inclusion of IL4 or TGF $\beta 1$ with OSM+ TNF $\alpha$ resulted in a marked reduction of the membrane associated aggrecanase activity while both of these antiinflammatory agents failed to induce the activity when used alone (fig 1B).
Neither TIMP-1 nor TIMP-2 caused any significant inhibition of the membrane associated aggrecanase, as was previously reported for IL1+OSM. ${ }^{41}$ However, inclusion of TIMP-3 almost completely inhibited this activity even at the lowest concentration used (fig $\mathrm{lC}$ ), suggesting that this activity is a metalloproteinase such as an ADAM or ADAMTS.

OSM in combination with TNF $\alpha$ induces the expression of ADAMTS aggrecanases in chondrocytes

In bovine chondrocytes, OSM+TNF $\alpha$ enhanced ADAMTS-1, $-4,-5$, and -9 expression while ADAMTS-8 expression was

Bovine

Human
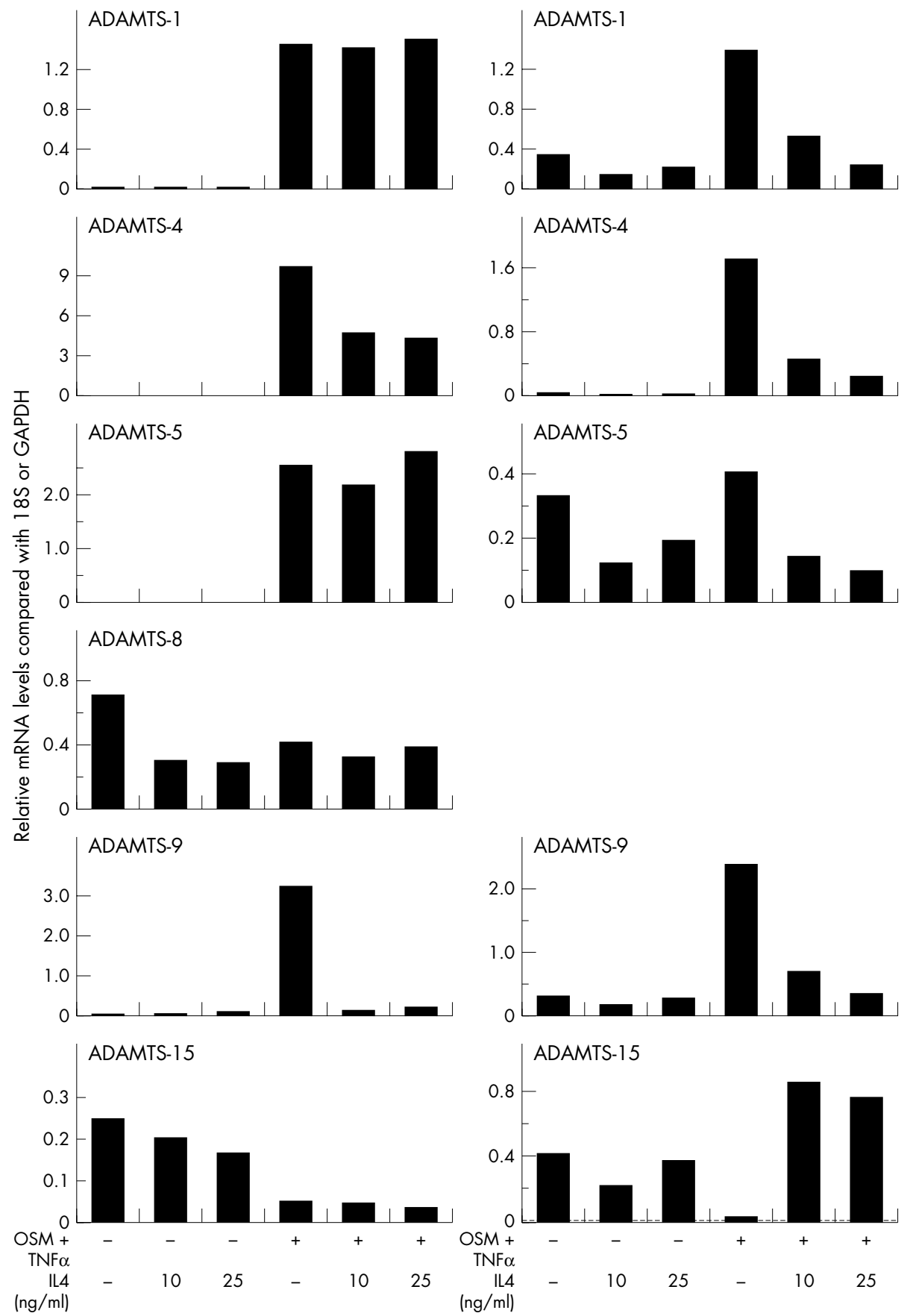

Figure 4 Effects of IL4 on OSM+TNF $\alpha$-induced ADAMTS aggrecanases. Bovine nasal or human articular chondrocytes were stimulated with OSM+TNF $\alpha$ (both at $10 \mathrm{ng} / \mathrm{ml}$ ) \pm IL4 for 24 hours. Real time PCR was performed on isolated RNA, and the normalised results presented graphically as described in fig 2. No signal was detected for ADAMTS-8 in human chondrocytes with any treatment. The data shown are representative of two separate chondrocyte preparations. 
relatively unaffected. All treatments appeared to reduce ADAMTS-15 expression compared with control (fig 2, bovine). In human articular chondrocytes, ADAMTS-1 and -4 mRNA appeared to be dose dependently up regulated by the OSM+TNF $\alpha$ combinations at 24 hours. A minor, but consistent induction of ADAMTS-4 mRNA was seen after either OSM or TNF $\alpha$ stimulation. ADAMTS- 5 was constitutively expressed, and this expression was reduced by both OSM and TNF $\alpha$. The OSM+TNF $\alpha$ combination failed to increase this expression above basal levels. TNF $\alpha$ enhanced ADAMTS-9 expression, although inclusion of OSM markedly decreased this TNF $\alpha$ stimulated expression. Cytokines alone, and in combination, appeared to decrease ADAMTS-15 expression compared with control (fig 2, human). We failed to detect ADAMTS-8 mRNA in human chondrocytes (not shown). Similar profiles were also found at 6 and 12 hour time points for both bovine and human chondrocytes (data not shown).

\section{TGF $\beta 1$ and IL4 have differential effects on OSM+TNF $\alpha$ - induced ADAMTS aggrecanase mRNA expression in chondrocytes}

Addition of TGF $\beta 1$ to bovine chondrocytes increased both basal and OSM+TNF $\alpha$ stimulated levels of ADAMTS-1, -4, and -5 . Basal levels of ADAMTS- 8 and -9 were unaffected while the relatively low levels of ADAMTS-15 were suppressed. OSM+TNF $\alpha$-induced levels of ADAMTS-8 and - 15 were not notably affected by TGF $\beta 1$, but ADAMTS-9 levels were markedly lower (fig 3, bovine). In human chondrocytes, the relatively low basal ADAMTS expression levels were moderately suppressed by TGF $\beta 1$ except for a more marked reduction for ADAMTS-15 (fig 3, human). Again, similar profiles at 6 and 12 hour time points were found (data not shown).

IL4 had little effect on basal ADAMTS expression levels in bovine chondrocytes except for a modest suppression for ADAMTS-8 and -15. For OSM+TNF $\alpha$-induced ADAMTS expression, IL4 had no affect on ADAMTS-1, -5, -8, or -15, but suppressed both ADAMTS-4 and -9 expression (fig 4, bovine). For human chondrocytes, IL4 again had little effect on basal ADAMTS expression except modest suppressions for ADAMTS-1, -5, and -15, although this was more pronounced for OSM+TNF $\alpha$-induced ADAMTS- $1,-4,-5$, and -9 but not ADAMTS-15 (fig 4, human). Similar results were observed at 6 and 12 hour time points (data not shown).

\section{DISCUSSION}

The breakdown of aggrecan and collagen from cartilage leads to a significant loss of functionality of its extracellular matrix. Collagen loss has been attributed to the collagenolytic MMPs-most notably, MMP-1 and -13, although this is dependent on the degenerative disorder. ${ }^{49}$ These enzymes are up regulated by a plethora of proinflammatory cytokines, and several cytokine combinations have now been shown to synergistically induce these proteinases. ${ }^{26-28}{ }^{50}$ Most of these cytokines also induce proteoglycan loss from cartilage, an event that typically precedes collagen loss. ${ }^{928}$ Several MMPs are known to cleave aggrecan, ${ }^{1}$ although cleavage at the Glu373-Ala374 bond is considered to be the mechanism of pathological aggrecan degradation in cartilage. ${ }^{2}$ The discovery of two aggrecanases-namely, ADAMTS-4 and -5, represented a watershed in matrix biology. ${ }^{35}$ However, since these discoveries conflicting data have been reported about the identity of the proteinases that are responsible for aggrecan degradation. Early studies suggested that proteoglycan release from cartilage occurred at the cell surface, ${ }^{51}{ }^{52}$ and our own work has demonstrated an aggrecanase activity associated with the chondrocyte membrane. ${ }^{41}$ Our data also indicate that this activity is not readily solubilised from membrane preparations (unpublished data), suggesting that it may be an integral protein which would exclude the possibility of it being a soluble proteinase such as one of the ADAMTS aggrecanases..$^{3-8}$

This study confirms that the combination of OSM+TNF $\alpha$ also induces this membrane associated aggrecanase which has a similar activity against aggrecan to that of other aggrecanases, in that it cleaves aggrecan monomer at multiple sites. ${ }^{18}$ Moreover, this activity is inhibited if either IL4 or TGF $\beta 1$, both chondroprotective agents, are present. OSM alone induced weak activity, and although it does not induce any of the ADAMTS aggrecanases it does promote cartilage aggrecanolysis. ${ }^{28}$ TNF $\alpha$ also mediates aggrecan release, ${ }^{23}$ and induced the membrane associated aggrecanase in this study. Interestingly, in vitro assays using aggrecanase neoepitope recognition failed to detect soluble TNF $\alpha$-induced aggrecanase activity, although exogenous addition of deglycosylated aggrecan blocked aggrecan release from bovine cartilage. ${ }^{24}$ Possibly, therefore, TNF $\alpha$-induced aggrecan release is partly mediated by ADAMTS-4 because this aggrecanase is modestly up regulated by this growth factor, but the synergistic release of proteoglycan from cartilage $^{28}$ might be explained by the presence of a new

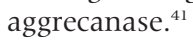

TIMP-3 has been shown to inhibit ILl and retinoic acid mediated proteoglycan release, ${ }^{38}$ and our data also confirm the ability of TIMP-3 to inhibit the proteolytic action of the chondrocyte membrane associated aggrecanase. However, differences were seen between the ILl and retinoic acid treatments, which may be explained by the action of hyaluronidases..$^{53}$ Although TIMP-3 has been shown to potently inhibit ADAMTS-4 and $-5,{ }^{36} 37$ the identity of the specific aggrecanase(s) susceptible to TIMP-3 inhibition in these ex vivo studies remains unknown. ${ }^{38}$ Our data also indicated that neither TIMP-1 nor TIMP-2 inhibited the membrane associated aggrecanase even at $>10$-fold molar excess compared with TIMP-3.

Comparison of this membrane associated aggrecanase activity and ADAMTS aggrecanase gene expression in bovine chondrocytes (stimulated under the identical conditions that generate the membrane aggrecanase activity) excludes ADAMTS- $1,-4,-5,-8$, and -15 because the expression profiles of these enzymes do not coincide with that of the membrane activity. This therefore leaves ADAMTS-9 as a possible candidate as it as been shown that this soluble enzyme can localise to the cell surface. ${ }^{6}$ However, in cell based assays, ADAMTS- 9 cleaves versican at the same Glu-Ala bond as ADAMTS-4, but was barely active against aggrecan compared with ADAMTS-4, although aggrecanase activity at the Glu373-Ala374 bond was not assessed. ${ }^{6}$ Although this does not definitively preclude ADAMTS-9 as the membrane associated aggrecanase described in the present study, data from human articular chondrocytes also support this exclusion because ADAMTS- 9 is induced by TNF $\alpha$ but reduced by OSM. Another important point here is that this membrane associated aggrecanase hydrolyses deglycosylated aggrecan monomer, a property not attributed to aggrecanases such as ADAMTS $-4 .^{55}$

Activation of a constitutively produced aggrecanase such as ADAMTS-9 as a mechanism to explain OSM+TNF $\alpha$-induced membrane associated aggrecanase activity cannot be discounted. We have previously proposed that OSM contributes to cartilage collagenolysis by inducing potential activators of procollagenases. ${ }^{28}$ Indeed, although activation of constitutive ADAMTS- 4 has been reported for ILl, ${ }^{56}$ this mechanism is not universally accepted. Glycosylphosphatidyl inositol-anchored MMP-17 has been proposed to contribute to this activation, ${ }^{57}$ and a furin-like protease has also been suggested; indeed, our own data support the involvement of a furin-like activity in 
the pathways leading to proteoglycan degradation. ${ }^{58}$ A furin inhibitor blocks aggrecanase enzyme processing ${ }^{59}$ and furin levels are raised in diseased cartilage compared with normal. ${ }^{60}$ It is therefore apparent that aggrecanolysis is a complex process that most probably involves several distinct aggrecanase proteinases, depending on the type of stimulus, species, and age of the cartilage. ${ }^{53}$

Although TGF $\beta 1$ inhibited the membrane associated aggrecanase, we confirm that it induces ADAMTS- $4 .{ }^{15}$ These differential effects may therefore limit the potential therapeutic benefits of this growth factor, ${ }^{34}$ while IL4 appears to be able to block the action of collagenases ${ }^{30}{ }^{31}$ and aggrecanases. Our own data support the notion that a new membrane associated aggrecanase may contribute significantly to proinflammatory cytokine induced aggrecanolysis, and a better understanding of the complexity involved is critical in the identification of new therapeutic targets that prevent cartilage degradation.

\section{ACKNOWLEDGEMENTS}

This work was funded by the Wellcome Trust, the Arthritis Research Campaign, the Dunhill Medical Trust, the Anne Coleman Fund, and the JGW Patterson Trust. We thank John Heath and Dave Buttle for their reagents. There are no competing interests.

\section{Authors' affiliations}

W Hui, H E Barksby, D A Young, T E Cawston, N McKie, A D Rowan, Musculoskeletal Research Group, School of Clinical Medical Sciences, University of Newcastle upon Tyne, Newcastle NE2 4HH, UK

\section{REFERENCES}

1 Nagase $\mathbf{H}$, Kashiwagi $M$. Aggrecanases and cartilage matrix degradation. Arthritis Res Ther 2003;5:94-103.

2 Sandy JD, Verscharen C. Analysis of aggrecan in human knee cartilage and synovial fluid indicates that aggrecanase (ADAMTS) activity is responsible for the catabolic turnover and loss of whole aggrecan whereas other protease activity is required for $\mathrm{C}$-terminal processing in vivo. J Biochem 2001;358:615-26.

3 Tortorella MD, Burn TC, Pratta MA, Abbaszade I, Hollis JM, Liu R, et al. Purification and cloning of aggrecanase-1: a member of the ADAMTS family of proteins. Science 1999;284:1664-6.

4 Rodriguez-Manzaneque JC, Westling J, Thai SN, Luque A, Knauper V, Murphy $G$, et al. ADAMTS1 cleaves aggrecan at multiple sites and is differentially inhibited by metalloproteinase inhibitors. Biophys Res Commun 2002;293:501-8

5 Abbaszade I, Liu RQ, Yang F, Rosenfeld SA, Ross OH, Link JR, et al. Cloning and characterization of ADAMTS11, an aggrecanase from the ADAMTS family. J Biol Chem 1999;274:23443-50.

6 Somerville RP, Longpre JM, Jungers KA, Engle JM, Ross M, Evanko S, et al. Characterization of ADAMTS-9 and ADAMTS-20 as a distinct ADAMTS subfamily related to Caenorhabditis elegans GON-1. J Biol Chem 2003;278:9503-13

7 Collins-Racie LA, Flannery CR, Zeng W, Corcoran C, Annis-Freeman B, Agostino MJ, et al. ADAMTS-8 exhibits aggrecanase activity and is expressed in human articular cartilage. Matrix Biol 2004;23:219-30.

8 Porter S, Clark IM, Kevorkian L, Edwards DR. The ADAMTS metalloproteinases. Biochem J 2005;386:15-27.

9 Little CB, Hughes CE, Curtis CL, Janusz MJ, Bohne R, Wang-Weigand S, et al. Matrix metalloproteinases are involved in C-terminal and interglobular domain processing of cartilage aggrecan in late stage cartilage degradation. Matrix Biol 2002;21:271-88.

10 Lark MW, Bayne EK, Flanagan J, Harper CF, Hoerrner LA, Hutchinson N, et al. Aggrecan degradation in human cartilage. Evidence for both matrix metalloproteinase and aggrecanase activity in normal, osteoarthritic, and rheumatoid joints. J Clin Invest 1997;100:93-106.

11 Bluteau G, Conrozier T, Mathieu P, Vignon E, Herbage D, Mallein-Gerin F. Matrix metalloproteinase-1, $-3,-13$ and aggrecanase-1 and -2 are differentially expressed in experimental osteoarthritis. Biochim Biophys Acta 2001;1526:147-58

12 Vankemmelbeke MN, Holen I, Wilson AG, llic MZ, Handley CJ, Kelner GS, et al. Expression and activity of ADAMTS-5 in synovium. Eur J Biochem 2001;268:1259-68.

13 Bau B, Gebhard PM, Haag J, Knorr T, Bartnik E, Aigner T. Relative messenger RNA expression profiling of collagenases and aggrecanases in human articular chondrocytes in vivo and in vitro. Arthritis Rheum 2002;46:2648-57.

14 Flannery CR, Little CB, Hughes CE, Curtis CL, Caterson B, Jones SA. IL-6 and its soluble receptor augment aggrecanase-mediated proteoglycans catabolism in articular cartilage. Matrix Biol 2000;19:549-53.
15 Moulharat N, Lesur C, Thomas M, Rolland-Valognes G, Pastoureau P, Anract $P$, et al. Effects of transforming growth factor-beta on aggrecanase production and proteoglycan degradation by human chondrocytes in vitro. Osteoarthritis Cartilage 2004;12:296-305.

16 Malfait AM, Liu RQ, liji K, Komiya S, Tortorella MD. Inhibition of ADAM-TS4 and ADAM-TS5 prevents aggrecan degradation in osteoarthritic cartilage. J Biol Chem 2002;277:22201-8.

17 Kevorkian L, Young DA, Darrah C, Donell ST, Shepstone L, Porter S, et al. Expression profiling of metalloproteinases and their inhibitors in cartilage. Arthritis Rheum 2004;50:131-41

18 Arner EC, Pratta MA, Trzaskos JM, Decicco CP, Tortorella MD. Generation and characterization of aggrecanase. A soluble, cartilage-derived aggrecandegrading activity. J Biol Chem 1999;274:6594-601.

19 Yamanishi Y, Boyle DL, Clark M, Maki RA, Tortorella MD, Arner EC, et al. Expression and regulation of aggrecanase in arthritis: the role of TGF-beta. $\mathrm{J}$ Immunol 2002;168:1405-12.

20 Vazquez F, Hastings $G$, Ortega MA, Lane TF, Oikemus $S$, Lombardo $M$, et al. METH-1, a human ortholog of ADAMTS-1, and METH-2 are members of a new family of proteins with angio-inhibitory activity. J Biol Chem 1999;274:23349-57.

21 Clark ME, Kelner GS, Turbeville LA, Boyer A, Arden KC, Maki RA. ADAMTS9, a novel member of the ADAM-TS/metallospondin gene family. Genomics 2000;67:343-50

22 Brennan FM, Browne KA, Green PA, Jaspar JM, Maini RN, Feldmann, M. Reduction of serum matrix metalloproteinase 1 and matrix metalloproteinase 3 in rheumatoid arthritis patients following anti-tumour necrosis factor-alpha (cA2) therapy. Br J Rheumatol 1997;36:643-50.

23 Saklatvala J. Tumour necrosis factor alpha stimulates resorption and inhibits synthesis of proteoglycan in cartilage. Nature 1986;322:547-9.

24 Buttle DJ, Fowles A, llic MZ, Handley CJ. "Aggrecanase" activity is implicated in tumour necrosis factor alpha mediated cartilage aggrecan breakdown but is not detected by an in vitro assay. Mol Pathol 1997;50:153-9.

25 Manicourt DH, Poilvache P, Van Egeren A, Devogelaer JP, Lenz ME, Thonar EJ. Synovial fluid levels of tumor necrosis factor alpha and oncostatin $M$ correlate with levels of markers of the degradation of crosslinked collagen and cartilage aggrecan in rheumatoid arthritis but not in osteoarthritis. Arthritis Rheum 2000;43:281-8.

26 Hui W, Rowan $A D$, Richards CD, Cawston TE. Oncostatin M in combination with tumour necrosis factor- $\alpha$ induces cartilage damage and matrix metalloproteinase expression in vitro and in vivo. Arthritis Rheum 2003;48:3404-18.

27 Rowan AD, Hui W, Cawston TE, Richards CD. Adenoviral over-expression of oncostatin $M$ and interleukin-1 induces marked joint tissue damage and elevates matrix metalloproteinases in a murine model. Am J Pathol 2003; 162:1975-84.

28 Cawston TE, Curry VA, Summers CA, Clark IM, Riley GP, Life PF, et al. The role of oncostatin $M$ in animal and human connective tissue collagen turnover and its localization within the rheumatoid joint. Arthritis Rheum 1998;41:1760-71

29 Plater-Zyberk C, Buckton J, Thompson S, Spaull J, Zanders E, Papworth J, et al. Amelioration of arthritis in two murine models using antibodies to oncostatin M. Arthritis Rheum 2001:44:2697-702.

30 Cleaver CS, Rowan AD, Cawston TE. Interleukin 13 blocks the release of collagen from bovine nasal cartilage treated with proinflammatory cytokines. Ann Rheum Dis 2001;60:150-7.

31 van Lent PL, Holthuysen $A E$, Sloetjes $A$, Lubberts $E$, van den Berg WB. Local overexpression of adenoviral IL-4 protects cartilage from metalloproteinaseinduced destruction during immune complex-mediated arthritis by preventing activation of pro-MMPs. Osteoarthritis Cartilage 2002;10:234-43.

32 Hui W, Rowan AD, Cawston TE. Modulation of the expression of matrix metalloproteinase and tissue inhibitors of metalloproteinases by TGF-betal and IGF-1 in primary human articular and bovine nasal chondrocytes stimulated with TNF-alpha. Cytokine 2001;16:31-5.

33 Hui W, Rowan AD, Cawston TE. Transforming growth factor- $\beta 1$ blocked the release of collagen fragments from bovine nasal cartilage stimulated by oncostatin $M$ in combination with IL-1 $\alpha$. Cytokine 2000;12:765-9.

34 Grimaud E, Heymann D, Redini F. Recent advances in TGF-beta effects on chondrocyte metabolism. Potential therapeutic roles of TGF-beta in cartilage disorders. Cytokine Growth Factor Rev 2002;13:241-57.

35 Su S, Grover J, Roughley PJ, DiBattista JA, Martel-Pelletier J, Pelletier JP, et al. Expression of the tissue inhibitor of metalloproteinases (TIMP) gene family in normal and osteoarthritic joints. Rheumato Int 1999; 18:183-91.

36 Kashiwagi $M$, Tortorella M, Nagase H, Brew K. TIMP-3 is a potent inhibitor of aggrecanase 1 (ADAM-TS4) and aggrecanase 2 (ADAM-TS5). J Biol Chem $2001 ; 276: 12501-4$.

37 Hashimoto G, Aoki T, Nakamura H, Tanzawa K, Okada Y. Inhibition of ADAMTS4 (aggrecanase-1) by tissue inhibitors of metalloproteinases (TIMP-1, 2, 3 and 4). FEBS Lett 2001;494:192-5.

38 Gendron C, Kashiwagi M, Hughes C, Caterson B, Nagase H. TIMP-3 inhibits aggrecanase-mediated glycosaminoglycan release from cartilage explants stimulated by catabolic factors. FEBS Lett 2003;555:431-6.

39 Cawston T, Billington C, Cleaver C, Elliott S, Hui W, Koshy P, et al. The regulation of MMPs and TIMPs in cartilage turnover. Ann N Y Acad Sci 1999;878:120-9

40 Hui W, Cawston TE, Rowan AD. Transforming growth factor beta 1 and insulin-like growth factor 1 block collagen degradation induced by oncostatin $M$ in combination with tumour necrosis factor alpha from bovine cartilage. Ann Rheum Dis 2003;62:172-4.

41 Billington CJ, Clark IM, Cawston TE. An aggrecan-degrading activity associated with chondrocyte membranes. Biochem J 1998;336:207-12. 
42 Vankemmelbeke MN, llic MZ, Handley CJ, Knight CG, Buttle DJ. Coincubation of bovine synovial or capsular tissue with cartilage generates a soluble "aggrecanase" activity. Biochem Biophys Res Commun 1999:255:686-91.

43 Hodges DJ, Reid DG, Rowan AD, Clark IM, Cawston TE. Preparation of recombinant tissue inhibitor of metalloproteinases-1 (TIMP-1) in high yield and identification of a hydrophobic surface feature. Eur J Biochem 1998;257:562-9.

44 Arris CE, Bevitt DJ, Mohamed J, Li Z, Langton KP, Barker MD, et al. Expression of mutant and wild-type TIMP3 in primary gingival fibroblasts from Sorsby's fundus dystrophy patients. Biochim Biophys Acta 2003;1638:20-8.

45 Curry VA, Clark IM, Bigg H, Cawston TE. Large inhibitor of metalloproteinases (LIMP) contains tissue inhibitor of metalloproteinases (TIMP)-2 bound to 72,000-M(r) progelatinase. Biochem J 1992;285:143-7.

46 Luzio JP, Stanley KK. The isolation of endosome-derived vesicles from rat hepatocytes. Biochem J 1983;216:27-36.

47 Hascall VC, Sajdera SW. Proteinpolysaccharide complex from bovine nasal cartilage. The function of glycoprotein in the formation of aggregates. J Biol Chem 1969;244:2384-96

48 Koshy PJ, Lundy CJ, Rowan AD, Porter S, Edwards DR, Hogan A, et al. The modulation of matrix metalloproteinase and ADAM gene expression in human chondrocytes by interleukin- 1 and oncostatin $M$ : a time-course study using real-time quantitative reverse transcription-polymerase chain reaction. Arthritis Rheum 2002;46:961-7.

49 Poole AR, Nelson F, Dahlberg L, Tchetina E, Kobayashi M, Yasuda T, et al. Proteolysis of the collagen fibril in osteoarthritis. Biochem Soc Symp 2003;70:1 15-23.

50 Koshy PJT, Henderson N, Logan C, Life PF, Cawston TE, Rowan AD. Interleukin-17 induces cartilage collagen breakdown: novel synergistic effects in combination with pro-inflammatory cytokines. Ann Rheum Dis 2002;61:704-13.

51 Dingle JT, Dingle $\Pi$. The site of cartilage matrix degradation. Biochem J 1980;190:431-8.
52 Morales TI, Hascall VC. Correlated metabolism of proteoglycans and hyaluronic acid in bovine cartilage organ cultures. J Biol Chem 1988;263:3632-8.

53 Sztrolovics R, White RJ, Roughley PJ, Mort JS. The mechanism of aggrecan release from cartilage differs with tissue origin and the agent used to stimulate catabolism. Biochem J 2002;362:465-72.

54 Sztrolovics R, Recklies AD, Roughley PJ, Mort JS. Hyaluronate degradation as an alternative mechanism for proteoglycan release from cartilage during interleukin-1 beta-stimulated catabolism. Biochem J 2002;362:473-9.

55 Tortorella $M$, Pratta $M$, Liu RQ, Abbaszade I, Ross $H$, Burn $T$, et al. The thrombospondin motif of aggrecanase-1 (ADAMTS-4) is critical for aggrecan substrate recognition and cleavage. J Biol Chem 2000;275:25791-7.

56 Pratta MA, Scherle PA, Yang G, Liu RQ, Newton RC. Induction of aggrecanase 1 (ADAM-TS4) by interleukin-1 occurs through activation of constitutively produced protein. Arthritis Rheum 2003;48:119-33.

57 Gao G, Plaas A, Thompson VP, Jin S, Zuo F, Sandy JD. ADAMTS4 (aggrecanase-1) activation on the cell surface involves C-terminal cleavage by glycosylphosphatidyl inositol-anchored membrane type 4-matrix metalloproteinase and binding of the activated proteinase to chondroitin sulfate and heparan sulfate on syndecan-1. J Biol Chem 2004;279: 10042-51.

58 Milner JM, Rowan AD, Elliott SF, Cawston TE. Inhibition of furin-like enzymes blocks interleukin-1 alpha/oncostatin M-stimulated cartilage degradation. Arthritis Rheum 2003;48:1057-66.

59 Gao G, Westling J, Thompson VP, Howell TD, Gottschall PE, Sandy JD. Activation of the proteolytic activity of ADAMTS4 (aggrecanase-1) by Cterminal truncation. J Biol Chem 2002;277:1 1034-41.

60 Moldovan F, Pelletier JP, Mineau F, Dupuis M, Cloutier JM, Martel-Pelletier J. Modulation of collagenase 3 in human osteoarthritic cartilage by activation of extracellular transforming growth factor beta: role of furin convertase. Arthritis Rheum 2000;43:2100-9. 